International Journal of Scholarly Papers for Media and Society Research

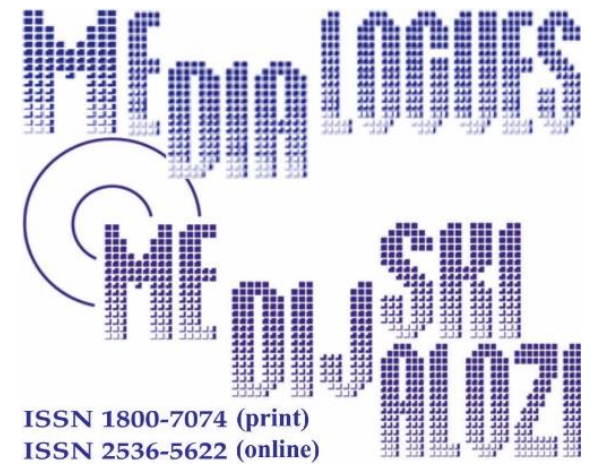

Bojovic, B. (2012), „Reality Show and Rhetoric”, Media Dialogues / Medijski dijalozi, Vol. 14, No. 3, pp. 89-96.

\title{
Reality Show and Rhetoric
}

\author{
Assistant professor BRANKICA BOJOVIC, \\ University of Montenegro, Faculty of Philosophy, \\ Niksic, Montenegro
}

\begin{tabular}{|c|c|}
\hline $\begin{array}{l}\text { ARTICLE } \\
\text { INFO }\end{array}$ & $\begin{array}{l}\text { Received: September 11,2020 / Revised from: October 10, } 2020 \\
\text { Accepted: November 12,2020 / Available online: April 12, } 2021\end{array}$ \\
\hline DOI & doi.org/10.14254/1800-7074/14-2/6 \\
\hline
\end{tabular}

\section{ABSTRACT}

The world's mass media system has changed, along with its quality and respectability. Through literary research and experimentation, it has been proven that people's perception of reality has been altered by the information they receive from television programmes. Television influences society in many ways. In the whole galaxy of media, reality shows are still the most intriguing ones. Theorists and researchers have tried to determine the issue of predictability that speaks about culture moving. Every norm is there to be respected or broken. The genre of reality television which has existed in some form or another since the early years of television programming, exploded as a phenomenon around 2000 with the success of such television 
series as Big Brother and Survivor. Nowadays, in our region, it is the Couples on Happy Kosava Television.

KEYWORDS: Reality show, experimentation, genre, motive, influence, audience, rhetoric, communications.

\section{INTRODUCTION}

Time we live in is the information technology age. People are easily swayed to accept a belief that they would not normally have unless it is expressed on television, since many people think that everything they hear on television is true. It has been observed that over the past twenty to thirty years, normal social behaviour, even the actual life roles of men and women, media and regulatory policies have all been altered (Browne, 1998).

Reality television is a genre of television programming that presents purportedly unscripted dramatic or humorous situations, documents actual events and usually features ordinary people instead of professional actors, sometimes in a contest or other situation where a prize is awarded. The genre, which has existed in some form or another since the early years of television programming, exploded as a phenomenon around 2000 with the success of such television series as Big Brother and Survivor. Programmes in the reality television genre are commonly called reality shows and often are produced in a television series. Documentaries, television news and sports television are usually not classified as reality shows.

Reality television frequ-ently portrays a modified and highly influenced form of reality, at times utilizing sensationalism to attract audience viewers and increase advertising revenue. The participants are often placed in exotic locations or abnormal situations, and are often persuaded to act in specific scripted ways by off-screen story editors or segment television producers with the portrayal of events and speech manipulated and contrived to create an illusion of reality through direction and postproduction techniques. A well-known example of a reality competition show is the globally syndicated Big Brother, in which cast members live together in the same house, with participants re-moved at regular intervals by either the viewing audience or in the American version by the participants them-selves.

\section{TYPES OF REALITIES}

There are various hybrid reality-competition shows, like the worldwide- syndicated Star Academy which combines the Big Brother and Idol formats. The Biggest Loser and The Pick-up Artist combine competition with the self-improvement format, and American Inventor uses the Idol format for products instead of people. Some shows such as Making the Band and Project Greenlight, devote the first part of 
the season to selecting a winner, and the second part to showing that person or group of people working on a project.

Many magazines and journal reviews have periodically discussed the muckraking that many tabloid shows rely on to draw in their viewers. This involves sensationalizing a story to make it more interesting, therefore increasing the interest of the audience. Along the way, all sorts of scandalous content and goofy tricks appear, but there is not much mystery in the logic. People often know that these shows aim to deceive them, but still accept the information as truth.

Though conforming is not necessarily bad, it can confuse people and therefore allow them to believe false ideas. When someone is under an informational social influence and is willing to change their views, the fine line between truth and fiction is clouded.

Television is in the convenient position of being able to influence people when they are most vulnerable. Open-mindedness can often be treated as gullibility and therefore used as a tool to manipulate people's beliefs. Daschmann stated a reason for this gullibility. He claims that a certain amount of gullibility or understanding of certain news shows comes with social factors. Some people are raised with a different education and status in society than others, which hinges on the perception of the different news shows and material. But the individual differences and character traits do not have a bearing on the subject matter (Daschmann \& Kepplinger, 1997).

The genre of reality television consists of various subgenres:

- a documentary style and within documentary style reality television are several subcategories or variants:

- special living environment,

- celebrities and

- professional activities.

Another sub-genre of reality TV is the reality competition or so-called reality game shows which follow the format of non-tournament elimination contests. A well- known example is Big Brother, where all cast members live in the same house. Popular variants of the competition-based format include:

- dating-based competitions,

- search for jobs, and

- sports.

Some reality television shows cover a person or group of people improving their lives. Sometimes the same group of people are covered over an entire season (as in The Swan and Celebrity Fit Club), but usually there is a new target for improvement in each episode. Despite differences in the content, the format is usually the same: 
- first, the show introduces the subjects in their current, less-than-ideal environment;

- then the subjects meet with a group of experts, who give the subjects instructions on how to improve things; they offer aid and encouragement along the way.

The subjects are placed back in their environment and they, along with their friends and family and the experts, appraise the changes that have occurred. Other self-improvement or makeover shows include: How Do I Look? (fashion makeover); The Biggest Loser and Fat March, (which covers weight loss); Extreme Makeover (entire physical appearance); Queer Eye and What not to wear (style and grooming); Supernanny (child-rearing); Made (attaining difficult goals); Trinny and Susannah Undress (fashion makeover and marriage); Tool Academy (relationship building); and, Charm School and From G's to Gents (self-improvement and manners - Wikipedia, 2012)

Some shows make over part or all of a person's living space, work space or vehicle. The American show This Old House was the first such show, debuting in 1979. The British show Changing Rooms, beginning in 1996 (later remade in the US as Trading Spaces) was the first such renovation show that added a gameshow feel with different weekly contestants. Other shows in this category include Extreme Makeover: Home Edition, Debbie Travis' Facelift, Designed to Sell, While You Were Out, Holmes on Homes, Pimp my ride and Overhauling Show Vehicles Being Rebuilt. Some shows, such as Restaurant Makeover and Ramsay's Kitchen Nightmares, show both the décor and the menu of a failing restaurant being remade. The issue of "making over" was taken to its social extreme with the British show Life Laundry, in which people who had become hoard- ers, even living in squalor, were given professional assistance.

Another type of reality programme is the social experiment that produces drama, conflict and sometimes transformation. Wife Swap, which began in 2003 on Channel 4 and has aired for four seasons on ABC, is a notable example. People with different values agreed to live by each other's social rules for a brief period of time and sometimes learn from the experience. Other shows in this category include ITV's Holiday Showdown, Oxygen's The Bad Girls Club (lifestyles and actions), and Channel 4's Secret Millionaire. Faking It was a series where people had to learn a new skill and pass themselves off as experts in that skill. Shattered was a controversial 2004 UK series where contestants competed for how long they could go without sleep.

Another reality programme features hidden cameras when random passers-by encounter a staged situation. Candid Camera, which first aired on television in 1948, pioneered the format. Modern variants of this type of production include for example The Jamie Kennedy Experiment and Just for Laughs: Gags. 


\section{ANALYSIS FOR AND AGAINST REALITY SHOWS}

Reality television's global success has been, in the eyes of some analysts, an important political phenomenon. In some authoritarian countries, reality television voting has been the first time many citizens have voted in any free and fair wide-scale elections. The frankness of the settings on some reality shows present situations that are often taboo in certain orthodox cultures, like Star Academy Arab World, which began airing in 2003, and which shows male and female contestants living together. In 2004, journalist Matt Labash, noting both of these issues, wrote that "the best hope of little Americas developing in the Middle East could be Arab-produced reality TV". In China, after the finale of the 2005 season of Super Girl (the local version of Pop Idol) drew an audience of around 400 million people, and 8 million text message votes, the state-run English-language newspaper Beijing Today ran the front-page headline "Is Super Girl a Force for Democracy?" The Chinese government criticized the show, citing both its democratic nature and its excessive vulgarity, or "worldliness", and in 2006 banned it outright. Other attempts at introducing reality television have proved to be similarly controversial. A Pan-Arab version of Big Brother was cancelled in 2004 after less than two weeks on the air after a public outcry and street protests.

In 2007, Abu Dhabi TV began airing Million's Poet, a show featuring Pop Idolstyle voting and elimination, but for the writing and oration of Arabic poetry. The show became popular in Arab countries, with around 18 million viewers, partly because, according to analysts such as the University of Pennsylvania's Professor Marwan Kraidy, it was able to combine the excitement of reality television with a traditional, culturally relevant topic. In April 2010, however, the show also became a subject of political controversy, when Hilal, a 43-year-old female Saudi competitor, read out a poem criticizing her country's Muslim clerics. Hilal received the highest scores from the judges throughout the competition, and came in third place overall.

Can any form of entertainment, however, be truly good or bad in the general senntifying some of the six theses which overlap in the general topic of for and against reality shows:

\begin{tabular}{|c|c|}
\hline $\begin{array}{c}\text { FOR watching reality shows } \\
\text { it }\end{array}$ & AGAINST watching reality shows \\
\hline $\begin{array}{c}\text { a) teenagers get good enjoyment out of } \\
\text { (public forum) }\end{array}$ & $\begin{array}{c}\text { a) it has a bad influence on the } \\
\text { audience }\end{array}$ \\
\hline c) a major boost in self-confidence & c) extreme profit motive \\
\hline $\begin{array}{c}\text { d) something new, not the same old } \\
\text { prepared monotonous programme }\end{array}$ & $\begin{array}{c}\text { d) audience and participants tend to } \\
\text { for- get that it is a media show at the } \\
\text { end of the day }\end{array}$ \\
\hline
\end{tabular}




\begin{tabular}{|c|c|}
\hline $\begin{array}{l}\text { e) provide an escape from everyday } \\
\text { life }\end{array}$ & $\begin{array}{c}\text { e) the most criticized sub-genre of } \\
\text { television programming }\end{array}$ \\
\hline f) totally ridiculous & \\
\hline
\end{tabular}

Some reality television participants think that it is pure entertainment, but delving a little deeper will reveal that many of its criticisms are well-warranted. The genre has made a name for itself by featuring dangerous stunts, deranged participants and outrageous displays of conduct, but are reality programmes bad for society?

In the end, as long as these programmes do not break any laws, why not have them? After all, the number of available TV channels is already tremendous and there is no sign of that number doing anything in the future but increasing. So if you only like one or two reality shows, it is not like the others are taking up valuable channel space or anything. I guess it all comes down to the fact that not everyone likes every type of entertainment. It is important to remember, however, that the main purpose of enter- tainment is to provide an escape from the demands of our everyday lives; something to take the "edge off" once in a while. If watching a reality show does that for you, then it has achieved its purpose. If not, watch something that does do that or find a completely different way to relax.

\section{RHETORIC CODE}

Rhetoric is the art of discourse, an art that aims to improve the facility of speakers or writers who attempt to inform, persuade, or motivate particular audiences in specific situations. The best known definition comes from Aristotle, who considers it a counterpart of both logic and politics, and calls it "the faculty of observing in any given case the available means of persuasion." Rhetoric typically provide heuristics for understanding, discovering and developing arguments for particular situations, such as Aristotle's three persuasive audience appeals: logos; pathos; and ethos.

The five canons of rhetoric, which trace the traditional tasks in designing a persuasive speech, were first codified in classical Rome: invention; arrangement; style; memory; and delivery. Along with grammar and logic, rhetoric is one of the three ancient arts of discourse. From Ancient Greece to the late 19th century, it was a central part of Western education, fulfilling the need to train public speakers and writers to move audiences to action with arguments.

Because of its associations with democratic institutions, rhetoric is commonly said to flourish in open and democratic societies with rights of free speech, free assembly and political enfranchisement for some portion of the population. Those who classify rhetoric as a civic art believe that rhetoric has the power to shape communities, from the character of citizens and greatly impact civic life. 
More trusting in the power of rhetoric to support a republic, the Roman orator Cicero argued that art required something more than eloquence. A good orator also needed to be a good man, a person enlightened on a variety of civic topics. He describes the proper training of the orator in his major text on rhetoric, De Oratore, modelled on Plato's dialogues.

\section{FEEDBACK IS IMMEDIATE, WHETHER POSITIVE OR NEGATIVE}

In interpersonal situations, feedback is sent immediately or almost simultaneously with your receiving a response. Feedback varies from the spontaneous and honest, to the carefully constructed response. Also, it can be positive or negative, meaning you pay a compliment to someone and support what the speaker says or you criticize someone and evaluate someone's acting and then the feedback is judgmental. Some- times feedback is easy to identify, but sometimes it is not (Skinner, 2002). Part of the art of effective communication is to discern feedback and adjust your messages on the basis of that feedback.

Feedback is examined in terms of five important dimensions (Devito, 2007):

- positive/negative;

- person-focused/message-focused;

- immediate/delayed;

- low monitoring/high monitoring; and

- supportive/critical.

\section{CONCLUSION}

People change in interpersonal communication for a variety of purposes. They change in order to learn about others and yourselves, to relate, to play, to influence, to help and to better understand the external world, i.e. other people. Sociolinguistically viewed, reality is a field of direct interdisciplinary examination of the language relations, with the basis of anthropology, discourse analysis, geolinguistics and languages in contact. (Wardhaugh, 2010). The structure of talking and politeness and way of speaking exist in interpersonal interaction. There are to be noticed various styles, genres and social classes as well as social multilingualism with communicators (Avramovic , 2006).

This is a good place to start practicing critical thinking skills in interpersonal communication. It has been shown that the better you communicate, the better communicator you become. The people inside the reality show are in some way connected because life takes place among them. The effectiveness of such communication and relation depends largely on interpersonal skills. Since skills are crucial for pro- 
fessional success in modern society, you are supposed to be a responsible citizen of the world, both socially and culturally as well as to be as open, empathic and supportive as you can be. When there is a conflict you should master the situation. That does not mean that you are never involved in conflict. Conflict is a very natural phenomenon is most human relationships. Conflict management ability is an extremely valuable pos- session when it comes to having great interpersonal skills.

Reality shows revolve around a specific issue or event that everybody can relate to, and out of that is built a game. They are in essence, game shows but also often dramatic social experiments. Another thing to remember is that some things are fun to play, and some things are fun to watch. To truly connect with an audience and have entertainment value in a show, you need both. The quality of a reality show can span from awful to inspiring. With the explosion of cable channels, many television genres are competing for market audience. Interpersonal communication and mass communication do not exist in isolation from one another, but they are complementary. The aim of this paper was to understand the relationship between viewer motives for watching reality shows and interpersonal relationship perceptions.

\section{REFERENCES}

Avramovic, Z. (2006), Culture, Institute for Textbooks and Teaching Aids, Belgrade (in Serbian).

Browne, K.D. (1998), Television and Media Effect on the Public, UK

Daschmann, G., Kepplinger, H. M., (1997), „Today's News-Tomorrow's Context: A

Dynamic Model of News Processing“, Journal of Broadcasting \& Electronic Media, Vol. 41, pp. 548-566.

Devito, J.A. (2007), The Interpersonal Communication Book, 12th Edition, USA.

Group of authors (2006), Media Education, Center for Media Professionalization and Institute of Social Sciences Belgrade (in Serbian).

Skinner, M. (2002), „In search of feedback“, Executive Excellence, June18.

Wardhaugh, R. (2010), An Introduction to Sociolinguistics, Blackwell Publishers Ltd, UK, Wikipedia, accessed March 2012. 